Original Research Paper

\title{
Effect of Novel Engineered Aspergillus oryzae on Soybean Meal Fermentation and Optimization of Cultivation Conditions
}

\author{
${ }^{1,2}$ Xiaochun Yu, ${ }^{1,2}$ Mingshuang Wang, ${ }^{1}$ Xin Su and ${ }^{1}$ Xuejiao Han \\ ${ }^{1}$ College of Food Science and Engineering, \\ Tonghua Normal University, 950 Yucai Road, Tonghua, Jilin 134002, P.R. China \\ ${ }^{2}$ Development Engineering Center of Edible Plant Resources of Changbai Mountain, \\ Tonghua Normal University, 950 Yucai Road, Tonghua, Jilin 134002, P.R. China
}

\author{
Article history \\ Received: 19-01-2020 \\ Revised: 26-02-2020 \\ Accepted: 19-03-2020 \\ Corresponding Author: \\ Xiaochun $\mathrm{Yu}$ \\ College of Food Science and \\ Engineering, Tonghua Normal \\ University, 950 Yucai Road, \\ Tonghua, Jilin 134002, P.R. \\ China \\ Tel:+86 13766144076 \\ Email: yuxc@thnu.edu.cn
}

\begin{abstract}
The filamentous fungus Aspergillus oryzae is an important strain in fermentation industry. In this study, to test the possibilities of improving polypeptides production, the soybean meal fermentation products were used to investigate the efficiencies of four different novel recombinant engineered $A$. oryzae strains $A$. oryzae subC, A. oryzae asp, A. oryzae Ap and $A$. oryzae pep. Gel filtration was employed to separate the products produced by the four engineered strains and wild-type A. oryzae and the antioxidant activities of each component of the products were compared. The results showed that the proportion of small-molecule peptides produced by $A$. oryzae pep fermentation was higher, mainly in the range of 1000-2000 Da, when compared with that yielded by wild-type A. oryzae fermentation. The antioxidant activities of the different components of the fermentation products produced by various engineered strains, especially component I of $A$. oryzae pep, showed varying degrees of improvement on DPPH and $\cdot \mathrm{OH}$ free radical scavenging activities, reaching $73.1 \% \pm 0.9 \%$ and $81.4 \% \pm 1.2 \%$, respectively. To further enhance the fermentation performance of $A$. oryzae pep, response surface methodology was used to optimize the fermentation conditions. The results indicated that the polypeptide conversion rate reached $40.4 \%$ following fermentation with $8 \%$ inoculum for $108 \mathrm{~h}$ at $31^{\circ} \mathrm{C}$. These findings are significant for the development of $A$. oryzae strains and high-value utilization of soybean meal resources.
\end{abstract}

Keywords: Engineered Aspergillus oryzae, Fermentation, Molecular Weight Distribution of Polypeptides, Antioxidation, Response Surface Optimization

\section{Introduction}

As a filamentous fungus belonging to the genus Aspergillus, Aspergillus oryzae has been traditionally used for more than 1000 years for brewing foods such as soybean paste and soy sauce (Abe et al., 2006). Owing to its easy cultivation and absence of aflatoxin secretion, A. oryzae is widely used in food processing and industrial enzymes production (Barbesgaard et al., 1992; Brown et al., 2013). A. oryzae mainly secretes neutral protease, with relatively low alkaline protease and acid protease activities, thus, presenting low degradation and utilization of raw protein (Zhao et al., 2014). To meet the needs of the fermentation industry, researchers are committed to develop new A. oryzae strains with high protease activity to improve raw protein utilization and composition of fermentation products (Ortiz et al., 2016; Xu et al., 2011; Fang et al., 2009). Genetic engineering has been reported to significantly enhance the protease activity of $A$. oryzae (te Biesebeke et al., 2005; Hunter et al., 2013; Olempska-Beer et al., 2006).

As the byproduct of oil processing industry, soybean meal has high protein content and is an excellent raw protein material (Zheng et al., 2017; Rumsey et al., 1994; Mukherjee et al., 2016). However, soybean meal is currently mainly used as feed, with only a small part of 
it employed in fermentation and the majority of the protein material not being effectively utilized, resulting in wastage of resources (Lawrence et al., 2003; Ortega et al., 2016; Nath et al., 2017). Thus, the use of soybean meal as a raw material for further processing and comprehensive utilization has significant prospects (Wang et al., 2017; Liu et al., 2017; Yu et al., 2018). Response Surface Methodology (RSM), which can accurately express the relationship between factors and response values, is an effective method to optimize reaction conditions. Because of its reasonable design and excellent results, it has been widely used in chemical industry, biological engineering and food engineering (Dai et al., 2018). In recent years, Box-Behnken design, an RSM with less factors and experiments, has gained more attention in the food industry, especially in the process of fermentation and optimization of operation conditions (Gunst, 2008).

In this study, engineered $A$. oryzae strains expressing different proteases were utilized for the fermentation of soybean meal. The molecular weight distribution and antioxidant activity of the fermentation products produced by different $A$. oryzae strains were compared and the fermentation conditions were optimized by RSM. The results of this study could help to develop high-yielding strains with desired properties, improve the yield of products and expand the use of soybean meal.

\section{Materials and Methods}

\section{Materials}

\section{Strains and chemicals}

Wild-type A. oryzae (huniang 3.042) preserved in our laboratory and four strains of engineered $A$. oryzae subC, A. oryzae asp, A. oryzae Ap and A. oryzae pep, which had been constructed before and preserved in our laboratory, were used in this study (Yu et al., 2017). The four genetically engineered $A$. oryzae strains expressed different proteases, respectively. Sephadex G-25 was obtained from Pharmacies Technology Co. Trypsin inhibitor $(M r 6511)$, vitamin B12 ( $M r$ 1355), glutathione ( $M r$ 307), DPPH and 3,5-dinitrosalicylic acid were purchased from Sigma Technology Co. Soybean meal was purchased from Yihai cereal oil.

\section{Activation and Cultivation of Strains}

The wild-type and four engineered A oryzae strains were activated on Potato Dextrose Agar slant medium (PDA) and cultured at $30^{\circ} \mathrm{C}$ for 3 days. The PDA medium contained the following: $20.0 \%$ potato, $2.0 \%$ agar and $2.0 \%$ glucose (sterilized at $121^{\circ} \mathrm{C}$ for $20 \mathrm{~min}$ ). Then, the spores were collected, washed with $10 \mathrm{~mL}$ of deionized water (sterilized). The spore solution was prepared and suspended at a concentration of $10^{8}$
spores/mL (Liu et al., 2009) and inoculated into solid fermentation medium (100 g) at $2 \%$ inoculum volume and $30^{\circ} \mathrm{C}$ for 4 days. The solid-state fermentation medium comprised the following: $0.1 \% \mathrm{KH}_{2} \mathrm{PO}_{4}, 0.04 \%$ $\mathrm{MgSO}_{4} \cdot 7 \mathrm{H}_{2} \mathrm{O}, 1.0 \%$ soluble starch and 1:1 soybean: Water. After the fermentation process, the fermented products were dried to constant weight using oven at $60^{\circ} \mathrm{C}$ for further analysis.

\section{Methods}

\section{Determination of Molecular Weight Distribution}

Samples of fermentation of different strains were extracted with deionized water in a water bath at $50^{\circ} \mathrm{C}$ for $6 \mathrm{~h}$. To inactivate the enzyme activity, the extracts were heated in an oven at $121 \mathrm{C}$ for $10 \mathrm{~min}$. The supernatant was obtained by centrifugation (Sorvall Stratos, Thermo, USA) at $3000 \times \mathrm{g}$ for $10 \mathrm{~min}$ and filtered by ultrafiltration (14-A, Ruili Shanghai, China) using an ultrafiltration membrane (cut-off molecular weight, $10 \mathrm{KDa}$ ) at $\mathrm{P}=0.12 \mathrm{MPa}(\mathrm{Ma}$ et al., 2001). Subsequently, the filtrate with molecular weight less than $10 \mathrm{kD}$ was collected, precooled for $2 \mathrm{~h}$ at $-40 \mathrm{C}$ in a vacuum freeze dryer (Scientz-30ND, Xinzhi Ningbo, China), freeze-dried for $10 \mathrm{~h}$ at a vacuum degree of less than $5 \mathrm{~Pa}$ and the samples were collected.

The molecular weight distribution of the peptides of the fermented products was determined by gel filtration (Xie et al., 2012). The column conditions comprised a flow rate of $1 \mathrm{~mL} / \mathrm{min}$ and detection wavelength of 280 $\mathrm{nm}$. As the elution buffer solution, $0.1 \mathrm{~mol} / \mathrm{L}$ Tris- $\mathrm{HCl}$ $(\mathrm{pH}$ 7.0) was employed. Subsequently, $5 \mathrm{~g}$ of Sephadex G-25 (Pharmacies) were added to $100 \mathrm{~mL}$ of deionized water, placed at room temperature for $3 \mathrm{~h}$ for swelling, packed in a column with chromatographic system (MA99, Huxi Shanghai, China) and eluted with buffer solution for $1 \mathrm{~h}$. The ultrafiltration samples of different strains with concentration of $5 \%(\mathrm{~W} / \mathrm{V})$ were prepared. Then, $2 \mathrm{~mL}$ of the samples were used for analysis under the above-mentioned conditions and the ultraviolet absorption of the effluent was recorded. The outflow volume $(\mathrm{mL})$ was recorded with a measuring cylinder and the analysis was repeated again under the same conditions. Trypsin inhibitor (Mr 6511), vitamin B12 (Mr 1355) and glutathione (Mr 307) were used as standard molecular weight references.

\section{Determination of Antioxidant Activity}

In this study, the antioxidant activities such as reduction potential, DPPH radical scavenging rate and hydroxyl radical scavenging rate of each component of the fermented products produced by different strains were tested. FRAP and KCN were used to determine the reduction potential and the components of the fermented products produced by different $A$. oryzae strains were 
compared by evaluating the absorbance of the reaction solution (Yen and Duh, 1993). The absorbance value was measured at $700 \mathrm{~nm}$ and the reduction potential of the sample was characterized by the absorbance value. The scavenging effects of different samples on DPPH free radicals were calculated by the method developed by Parejo et al. (2000), by detecting DPPH.scavenging at a wavelength of $517 \mathrm{~nm}$. Hydroxyl $(\mathrm{OH})$ radicals were determined by salicylic acid method (Li et al., 2008) and their concentration was calculated by adding salicylic acid into the system and detecting absorbance at $510 \mathrm{~nm}$.

\section{Optimization of the Fermentation Conditions}

RSM was applied to optimize the soybean meal fermentation conditions of engineered A. oryzae pep, which showed high content of small peptide and good antioxidant activity (Roldan-Carrillo et al., 2011). According to the design principle of the BoxBenhnken Center Combination Test, three factors that have significant influence on the polypeptides conversion rate were selected as follows: Fermentation time $\left(\mathrm{X}_{1}\right)$, fermentation temperature $\left(X_{2}\right)$ and inoculum volume $\left(X_{3}\right)$. Each factor was set at three levels: Low, medium and high. The factors were coded as $-1,0$ and 1 and the polypeptides conversion rate $(\mathrm{Y} / \%)$ was considered as the measures. Design Expert 8.0 software was used for test design. The factors and levels were set as shown in Table 1. The polypeptides conversion rates achieved by fermentation with different $A$. oryzae strains are shown in Table 2.
The polypeptides content was determined using the biuret method (Cotton et al., 1997). In brief, $5 \mathrm{~g}$ of the fermentation product were mixed with $10 \mathrm{~mL}$ of deionized water and placed in a water bath at $50^{\circ} \mathrm{C}$ for 6 h. The extracts were heated in an oven at $121 \mathrm{C}$ for 10 min to inactivate the enzyme activity. Then, equal volume of trichloroacetic acid solution (15\%) was added and the mixture was allowed to settle for $30 \mathrm{~min}$ to precipitate macromolecular proteins. The mixture was centrifuged at $5000 \times \mathrm{g}$ for $10 \mathrm{~min}$ at $4 \mathrm{C}$ (Sorvall Stratos, Thermo, USA) and the supernatant was stored in a $25-\mathrm{mL}$ tube at constant volume. Subsequently, $1 \mathrm{~mL}$ of the sample solution with 5-fold dilution was mixed with $4 \mathrm{~mL}$ of biuret reagent and stored at room temperature for $30 \mathrm{~min}$ and the absorbance of the mixture was measured at $540 \mathrm{~nm}$ with spectrophotometer (7200, Unico, China). The polypeptides content was determined by comparing with the standard curve obtained using casein (Sigma, USA) as the standard protein and the polypeptides conversion rate was calculated (Liu et al., 2011) as follows:

$$
\text { Polypeptides conversion rate }=\frac{\text { Polypeptides content }}{\text { soybean meal protein content }} \times 100 \%
$$

where soybean meal protein content is calculated as $\mathrm{M} \times 98.9 \% \times 42.6 \%$, with $\mathrm{M}$ denoting the amount of sample, $98.9 \%$ indicating the dry matter content in soybean meal and $42.6 \%$ representing the nitrogen content in soybean meal determined by Kjeldahl method (Deacon, 1972). The equation of the standard curve is: $y=0.0854 \mathrm{x}+0.0145$.

Table 1: Variables and levels used in the experimental design

\begin{tabular}{|c|c|c|c|c|c|}
\hline \multirow[b]{2}{*}{ Symbol } & \multirow[b]{2}{*}{ Variable } & \multicolumn{3}{|c|}{ Coded level } & \multirow[b]{2}{*}{ Unit } \\
\hline & & -1 & 0 & 1 & \\
\hline $\mathrm{X} 1$ & Fermentation time & 96 & 108 & 120 & $\mathrm{~h}$ \\
\hline $\mathrm{X} 2$ & Fermentation temperature & 30 & 32 & 34 & ${ }^{\circ} \mathrm{C}$ \\
\hline $\mathrm{X} 3$ & Inoculation volume & 2 & 4 & 8 & $\%$ \\
\hline
\end{tabular}

Table 2: Box-Behnken experimental design comprising three factors and three levels

\begin{tabular}{lllll}
\hline Run & $\mathrm{X}_{1}$ & $\mathrm{X}_{2}$ & $\mathrm{X}_{3}$ & Polypeptide conversion rate (Y)/\% \\
\hline 1 & 1 & 0 & -1 & 33.6 \\
2 & 1 & 0 & 1 & 37.1 \\
3 & -1 & 0 & -1 & 28.5 \\
4 & 0 & -1 & -1 & 34.6 \\
5 & 0 & 0 & 0 & 43.1 \\
6 & -1 & -1 & 0 & 25.8 \\
7 & -1 & 1 & 0 & 30.5 \\
8 & -1 & 0 & 1 & 34.7 \\
9 & 0 & 0 & 0 & 42 \\
10 & 0 & -1 & 1 & 38.2 \\
11 & 0 & 1 & -1 & 35.3 \\
12 & 1 & 1 & 0 & 30.7 \\
13 & 0 & 0 & 0 & 39.3 \\
14 & 0 & 1 & 1 & 36.3 \\
15 & 1 & -1 & 0 & 27.0 \\
\hline
\end{tabular}




\section{Results and Discussion}

\section{Molecular Weight Distribution of Polypeptides in the Fermented Products}

The results of gel filtration of the fermented products produced by different $A$. oryzae strains are shown in Fig. 1-5. The polypeptides in the fermented products produced by different strains were of various sizes and molecular weights and were continuously distributed. When compared with the fermented products produced by wild-type $A$. oryzae, the proportion of small molecular weight peptides in the fermented products produced by the engineered strains was higher, with A. oryzae pep exhibiting the largest peak area, indicating the higher percentage of small molecular peptides in the fermented products. When separated by chromatographic column, the peaks of the wild-type A. oryzae fermented products were at about $24 \mathrm{~min}$, while those of A. oryzae Ap and $A$. oryzae pep fermented products were at about 42 and $48 \mathrm{~min}$, respectively, indicating that the molecular weight of peptides in the fermented products of $A$. oryzae Ap and A. oryzae pep was lower than that of peptides in the fermented products of wild-type $A$. oryzae. The molecular weight distribution range of different components of the fermented products of each strain was determined from the molecular weight of standard protein. The molecular weight of the fermented product of $A$. oryzae pep was mainly in the range of 1000-2000 Da. The highest peak separation liquid of different strains fermented samples which the number of collection pipe is about 10-20 were collected and frozen dried respectively. These samples were recorded as gel filtration separation component I and used in subsequent tests.

Soybean polypeptide is a mixture of various peptides with different molecular weights. The molecular weight distribution of soybean polypeptide is closely related to its function. As peptide segments with different functional and physiological activities are often distributed in different molecular weight regions, it is crucial to understand the molecular weight composition of polypeptide (Suetsuna, 2000). It has been reported that during solid-state fermentation of soybean meal, microbial strains and their protease are involved in the degradation of soybean protein, increasing free amino acids, producing structural changes in soybean protein and improving the functional properties of soybean protein (Yang et al., 2013). Therefore, the microbial strains used in fermentation and their protease activity can affect the properties of the fermentation products. The results of the present study showed that the peptide composition of soybean meal fermented by different engineered strains of $A$. oryzae varied.

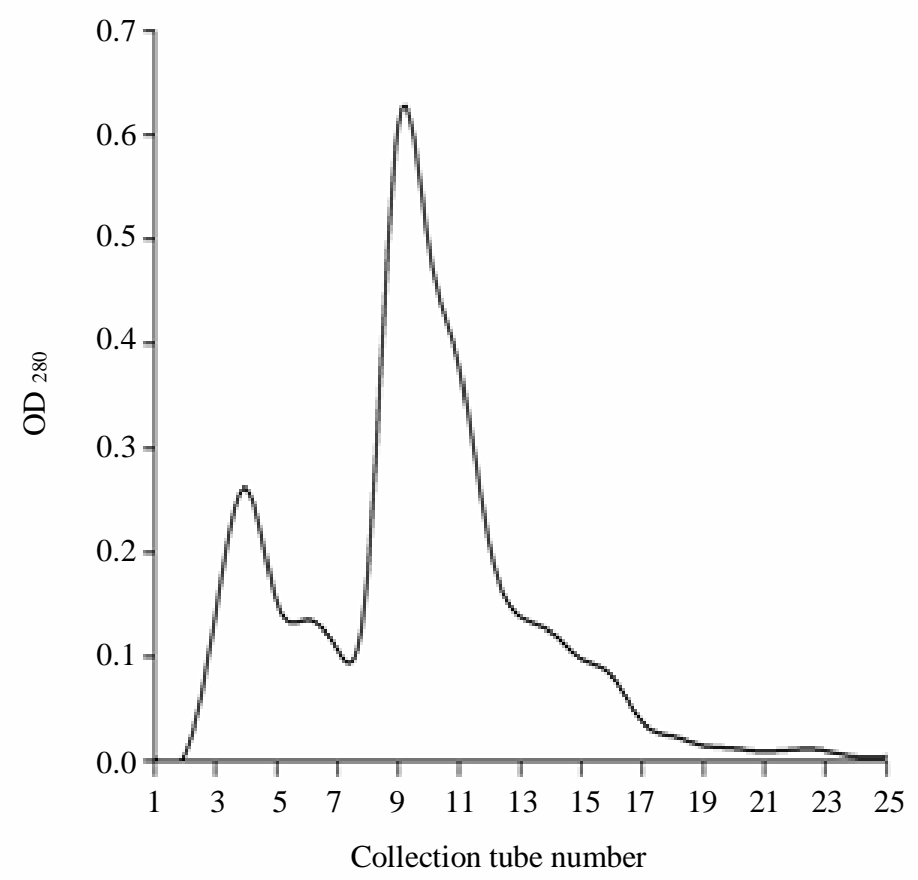

Fig. 1: Elution profile of ultrafiltrate of wild-type A. oryzae fermented product by Sephadex G-25 


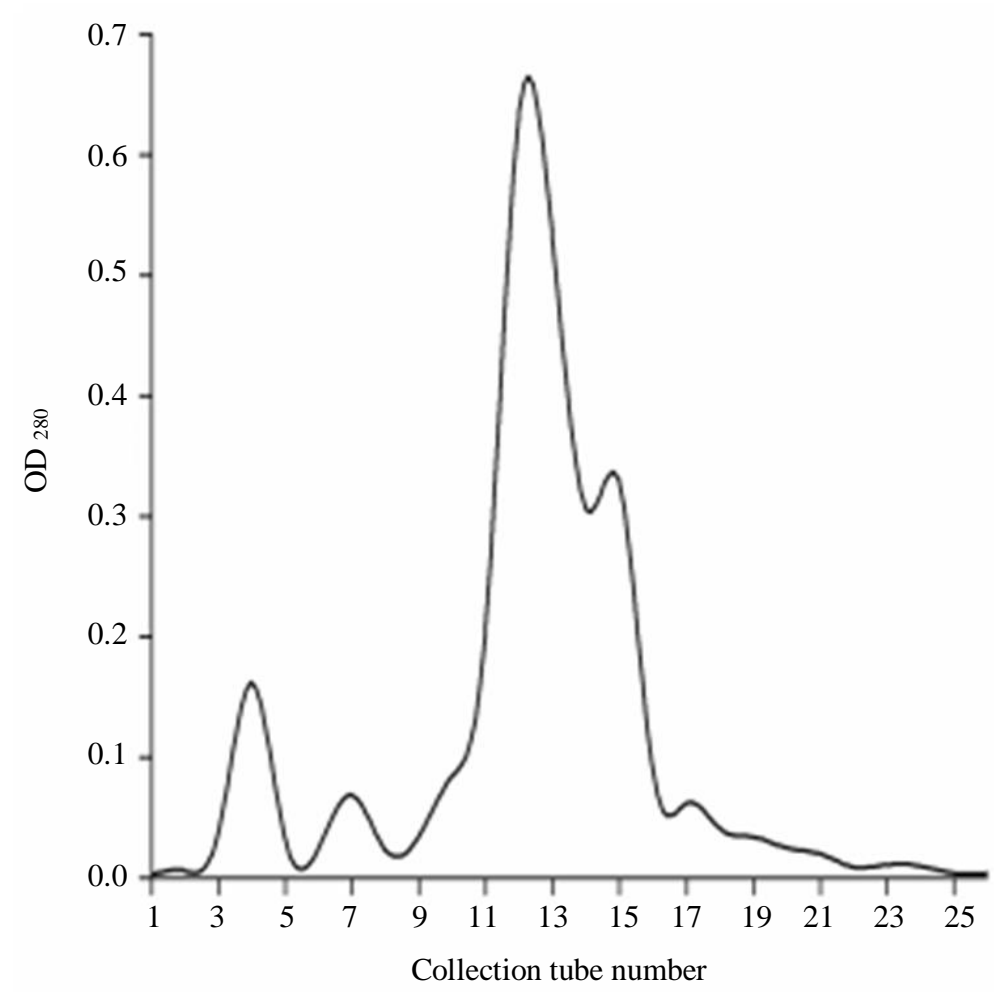

Fig. 2: Elution profile of ultrafiltrate of A. oryzae subC fermented product by Sephadex G-25

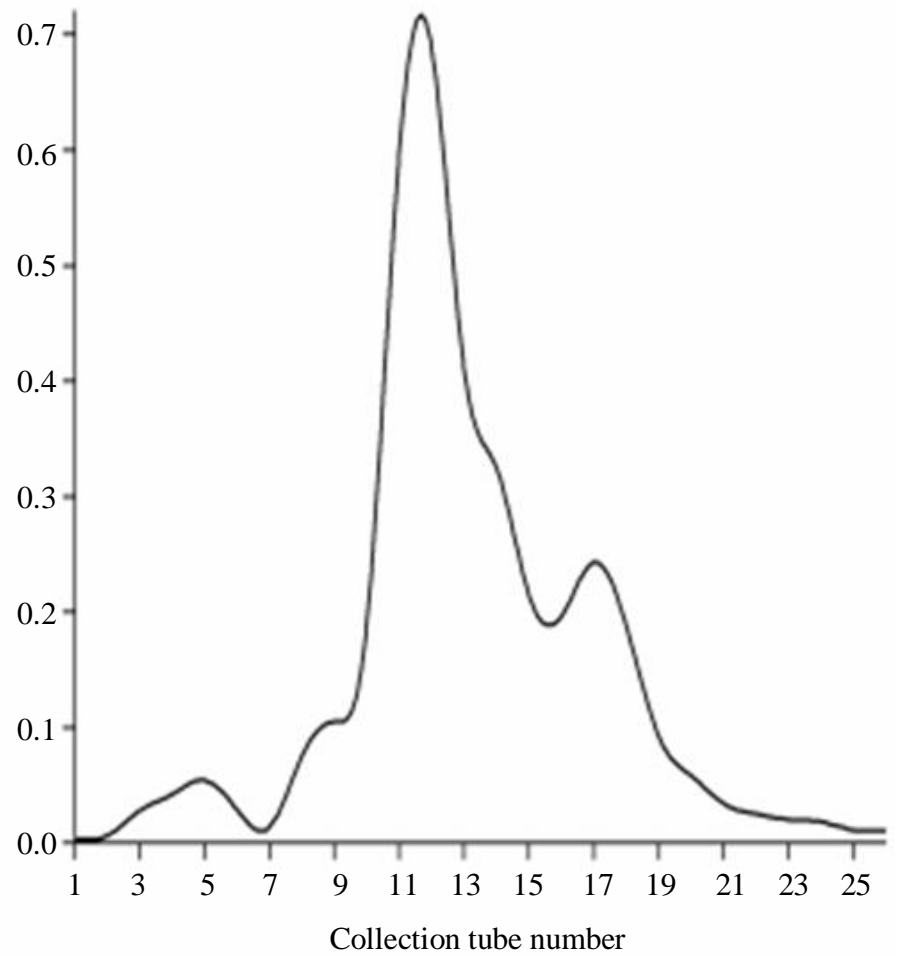

Fig. 3: Elution profile of ultrafiltrate of A. oryzae asp fermented product by Sephadex G-25 


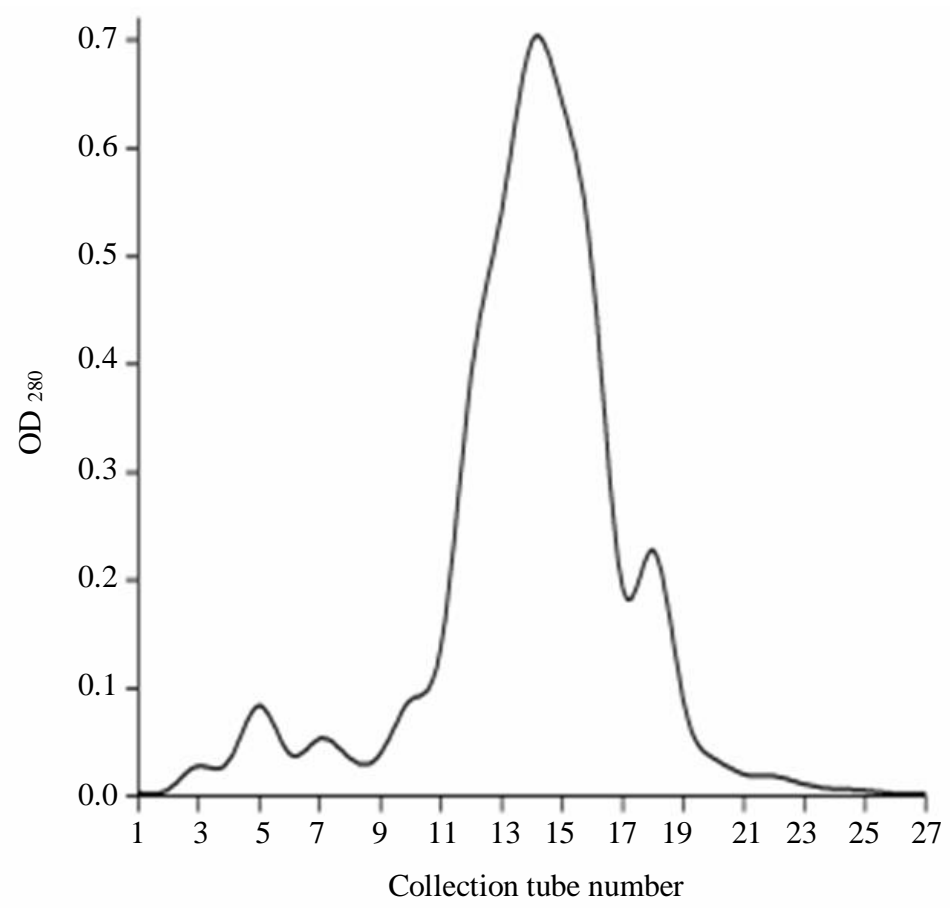

Fig. 4: Elution profile of ultrafiltrate of A. oryzae Ap fermented product by Sephadex G-25

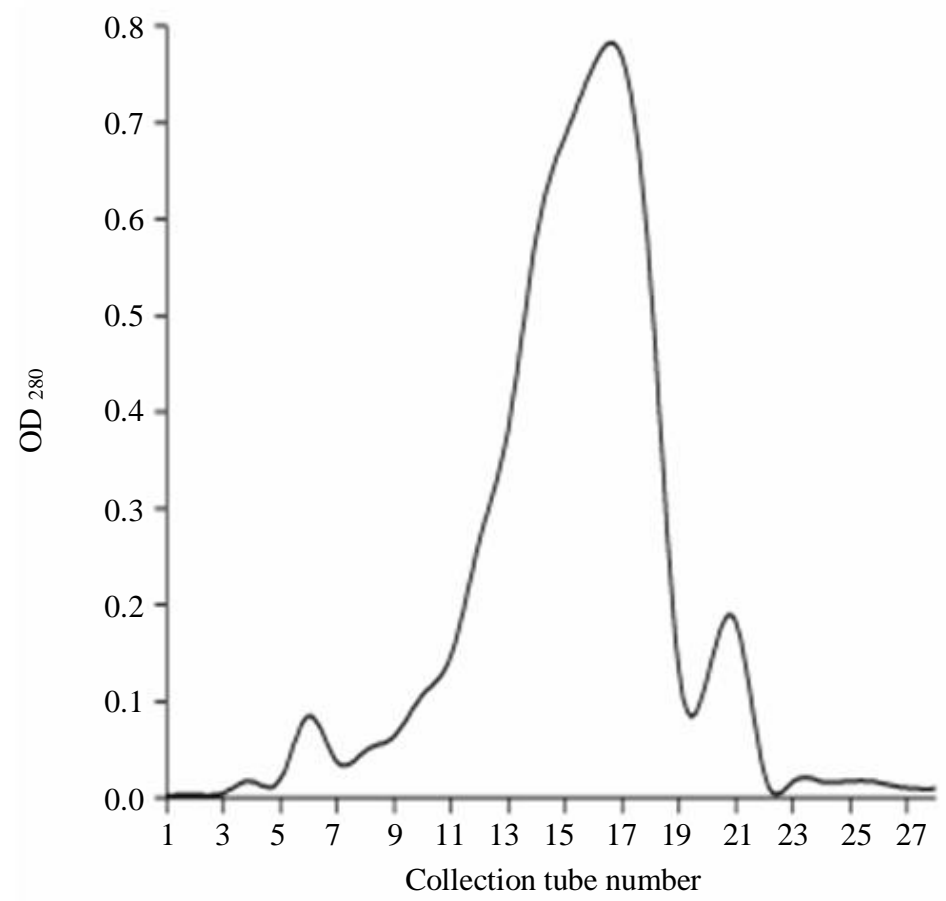

Fig. 5: Elution profile of ultrafiltrate of A. oryzae pep fermented product by Sephadex G-25

\section{Antioxidant Capacity of the Fermented Products}

Antioxidant capacity of fermented products is an important index, which can be evaluated by measuring the reduction ability of the products with potassium ferricyanide reduction system. The results of total reduction ability of each component of the fermented products produced by different $A$. oryzae strains are shown in Fig. 6. It can be observed from the figure that the total reduction ability of the fermented product 
extract, ultrafiltrate and gel filtration component I of different strains was improved at varying degrees after separation. The total reduction ability of component I of A. oryzae pep and A. oryzae Ap exhibited a higher increase. The absorbance value $\left(\mathrm{A}_{700}\right)$ of the fermented product extract, ultrafiltrate and component I of $A$. oryzae pep was $0.411,0.522$ and 0.766 , respectively. After ultrafiltration and gel filtration, the total reducibility of the components of the fermented products presented 1.9fold increase, when compared with that of the unfiltered fermented product. It has been indicated that soybean meal proteins may exhibit antioxidant activity and that the activity of the polypeptide is closely related to its molecular weight (Xu et al., 2015; Suetsuna, 2000). When compared with the absorbance value of wild-type $A$. oryzae component I, the total reduction capacity of $A$. oryzae pep component I was 1.3-fold higher.

The DPPH free radical scavenging activities of different components of the fermented products produced by different A. oryzae strains are shown in Fig. 7. It can be seen from the figure that the scavenging capacity of the fermented product extracts of wild-type A. oryzae, A. oryzae subC and $A$. oryzae asp showed only slight difference. The scavenging rates of $A$. oryzae Ap and $A$. oryzae pep extracts were slightly increased $(24.3 \% \pm 1.0 \%$ and $25.1 \% \pm 1.0 \%$, respectively), while that of component I and fermented product extract of A. oryzae pep presented the maximum value, reaching $73.1 \% \pm 0.9 \%$. The DPPH removal rate of $A$. oryzae pep ultrafiltrate $(42 \% \pm 0.9 \%)$ was 1.7-fold higher than that of the corresponding fermented extract $(25.1 \% \pm 1.0 \%)$. When compared with the fermented extract and ultrafiltrate, component I presented 2.9- and 1.7-fold higher clearance rate, respectively. These results showed that the DPPH scavenging activity of the fermented products improved with the decrease in the molecular weight of the polypeptides as well as increase in the proportion of small molecular peptides in the fermented products.

Currently, $\mathrm{OH}$ is the most active oxygen-containing free radical known and is also the most toxic free radical to living organisms (Chen et al., 2004). The scavenging effects of each component from different engineered $A$. oryzae strains on $\cdot \mathrm{OH}$ are shown in Fig. 8. It can be observed from the figure that the $\cdot \mathrm{OH}$ scavenging capacity of the fermented products produced by A. oryzae asp, A. oryzae Ap and A. oryzae pep was about $34 \% \pm 0.9 \%$, which was 1.5 -fold higher than that produced by the wild-type A. oryzae. In particular, the scavenging capacity of the fermented products produced by $A$. oryzae subC only slightly differed from that produced by wild-type $A$ oryzae, whereas the scavenging capacities of the fermented products and ultrafiltrate of $A$ oryzae asp was higher than those of wild-type $A$. oryzae. Moreover, the $\cdot \mathrm{OH}$ clearance rate of the fermented product produced by $A$. oryzae pep reached $81.4 \% \pm 1.2 \%$.

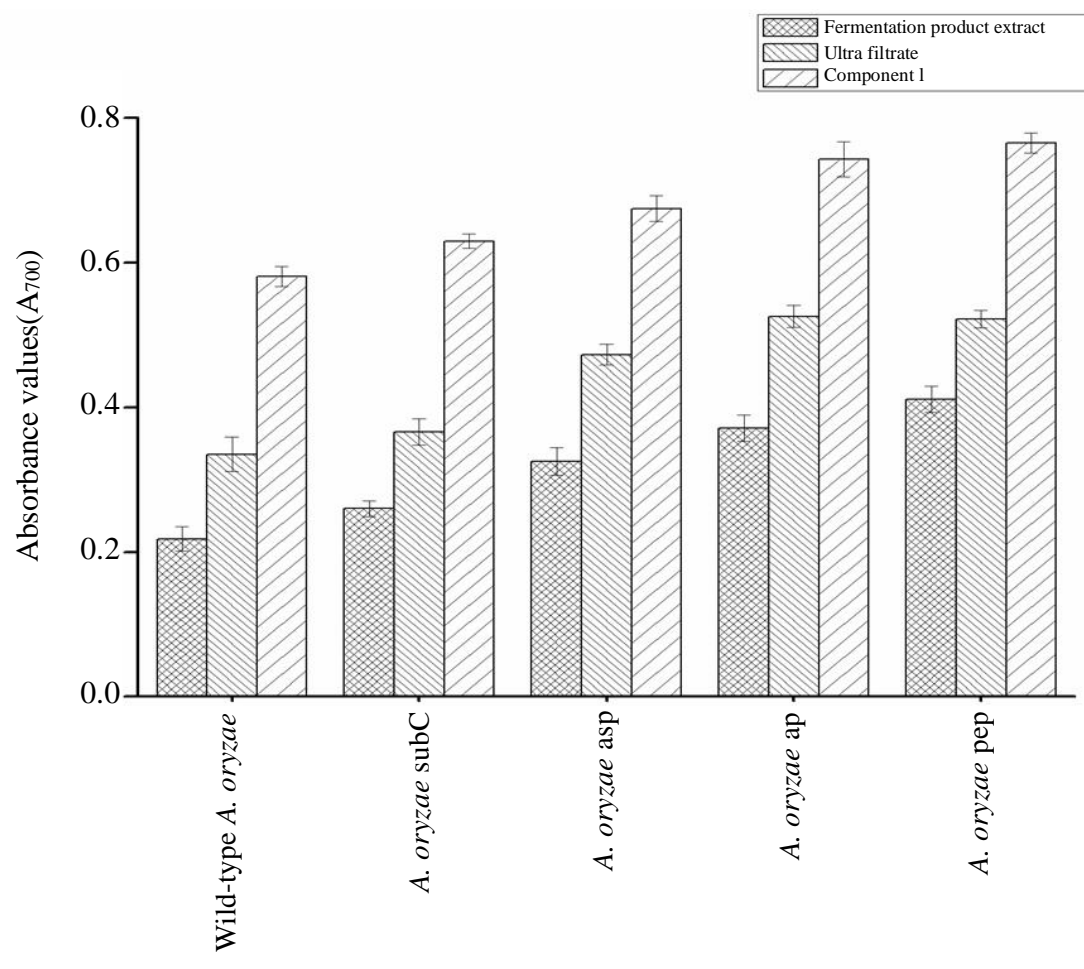

Components of different engineered strain fermented products

Fig. 6: Total antioxidant activity of the components of fermented products produced by different A. oryzae strains 


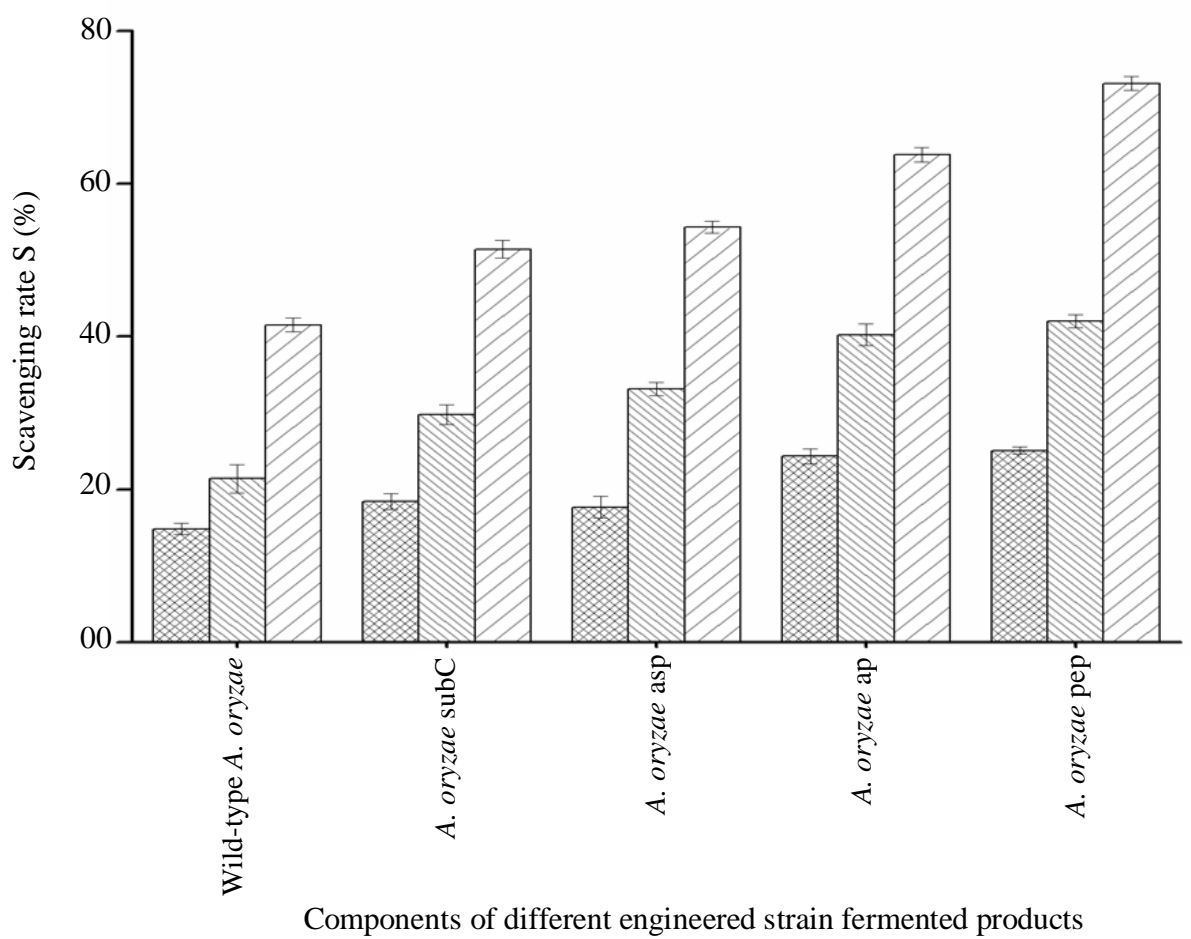

Fig. 7: DPPH radical scavenging activity of components of fermented products produced by different A. oryzae strains

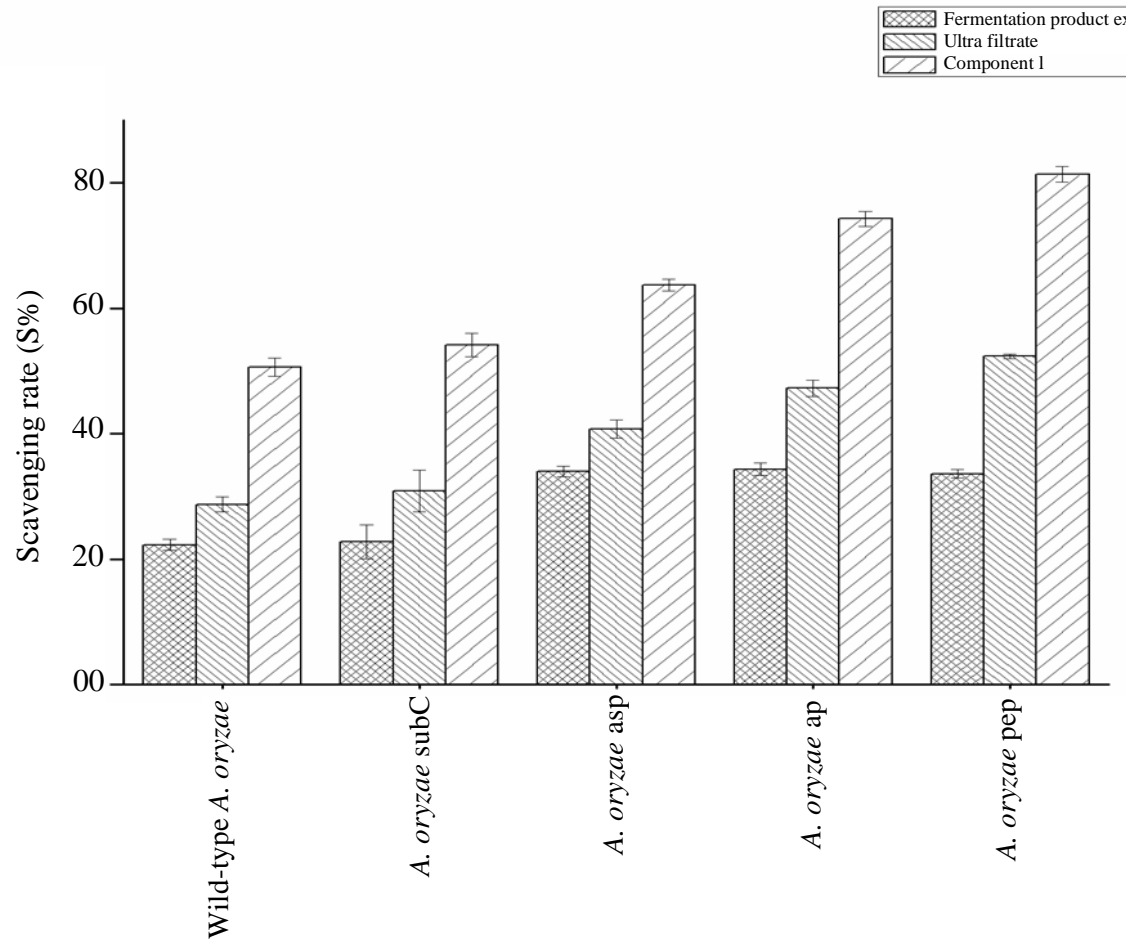

Components of different engineered strain fermented products

Fig. 8: $\mathrm{OH}$ radical scavenging activity of components of fermented products produced by different $A$. oryzae strains 
It has been reported that polypeptides derived from casein protein using pepsin and presenting molecular weights ranging from 913 to 2951 Da have better superoxide scavenging activity (Ibrahim et al., 2018). The antioxidant activity of polypeptides is the result of a combination of factors such as amino acid composition, amino acid sequence, molecular weight and spatial structure (Han et al., 2013). In the present study, the molecular weight and amino acid composition of polypeptides in the fermented products produced by $A$. oryzae pep were different from those of the polypeptides in the fermented products of wildtype $A$. oryzae, thus, resulting in varied antioxidant activities. Nevertheless, further studies on the amino acid composition and characteristics of polypeptides in the fermentation products produced by different engineered strains are needed.

\section{Optimization of Fermentation Conditions}

By using Design Expert 8.0 analysis software, the experimental data were fitted and analyzed and the quadratic polynomial regression equation was obtained as follows: $\mathrm{Y}=42.16+1.05 \mathrm{X}_{1}+0.73 \mathrm{X}_{2}+1.79 \mathrm{X}_{3}$ $0.25 \mathrm{X}_{1} \mathrm{X}_{2-} \quad 0.4 \mathrm{X}_{1} \mathrm{X}_{3}-0.99 \mathrm{X}_{2} \mathrm{X}_{3}-7.8 \mathrm{X}_{1}^{2}-5.17 \mathrm{X}_{2}^{2}-0.89 \mathrm{X}_{3}^{2}$. Table 3 shows the variance analysis of the regression model. It can be observed from the table that the $\mathrm{P}$ value of the model is significant, but the lack of fit is not significant, indicating the success of the experimental model. The regression coefficient $\mathrm{R}^{2}$ of response surface was 0.9317 , while the corrected Adj $\mathrm{R}^{2}$ was 0.8088 , revealing that the model had a good fit and small error and could be used to analyze and predict the fermentation conditions of soybean meal by A. oryzae. In the previous single-factor experiment, the effects of inoculum volume, fermentation time, fermentation temperature and moisture content in medium on polypeptide conversion rate were studied. The results showed that the influence of moisture content in medium on polypeptide conversion rate was not significant $(P>$ 0.05). Therefore, fermentation time, fermentation temperature and inoculum volume were selected in optimization test of RSM. The $\mathrm{F}$ value of variance analysis indicated that the degree of influence of each factor on polypeptides conversion rate presented the following trend: Inoculum size > fermentation time > fermentation temperature.

Figure 9 shows the response surface optimization of the conditions for fermentation with $A$. oryzae pep. It can be seen from the figure that the three charts of the response surface are convex with open ends facing downwards. The optimum fermentation conditions and fermentation results can be predicted according to the mathematical model established by the RSM. Under the conditions of fermentation time of $110 \mathrm{~h}$, fermentation temperature of $31.5^{\circ} \mathrm{C}$ and inoculum volume of $8 \%$, the theoretical polypeptides conversion rate obtained by RSM was $42.5 \%$. The fermentation conditions of validation experiment were adjusted considering the actual state of the fermentation experiment and feasibility of operation as follows: Fermentation time, $108 \mathrm{~h}$; fermentation temperature, $31^{\circ} \mathrm{C}$; and inoculum volume, $8 \%$. Under these adjusted conditions, the polypeptide conversion rate reached $40.4 \%$, which is in good agreement with the theoretical value, indicating that the established model is effective. The polypeptide conversion rate was 2.4 times higher than that achieved with the wild-type $A$. oryzae $(17.0 \%)$ and is higher than that reported in the literature. In a previous study using soybean meal as raw material, the soybean polypeptides conversion rate had reached $26.4 \%$ after fermentation with A. oryzae (Gao et al., 2014). In another study on soybean meal fermentation using Bacillus subtilis, the polypeptides conversion rate reached $31.5 \%$ after optimization of the fermentation process (Liao et al., 2012).

Table 3: ANOVA for response surface quadratic model

\begin{tabular}{llllll}
\hline Source & Sum of squares & df & Mean square & F value & P value* \\
\hline Model & 351.04 & 9 & 39.00 & 7.85 & 0.0191 \\
$\mathrm{X}_{1}$ (time) $h$ & 8.32 & 1 & 8.32 & 1.62 & 0.2596 \\
$\mathrm{X}_{2}$ (Temperature) ${ }^{\circ} \mathrm{C}$ & 4.10 & 1 & 4.10 & 0.80 & 0.4132 \\
$\mathrm{X}_{3}$ (volume) $\%$ & 25.56 & 1 & 25.56 & 4.97 & 0.0763 \\
$\mathrm{X}_{1} \mathrm{X}_{2}$ & 0.25 & 1 & 0.25 & 0.049 & 0.8343 \\
$\mathrm{X}_{1} \mathrm{X}_{3}$ & 0.67 & 1 & 0.67 & 0.13 & 0.7328 \\
$\mathrm{X}_{2} \mathrm{X}_{3}$ & 4.18 & 1 & 4.18 & 0.81 & 0.4089 \\
$\mathrm{X}_{1}{ }^{2}$ & 224.40 & 1 & 224.40 & 43.60 & 0.0012 \\
$\mathrm{X}_{2}{ }^{2}$ & 98.72 & 1 & 98.72 & 19.18 & 0.0072 \\
$\mathrm{X}_{3}{ }^{2}$ & 2.20 & 1 & 2.20 & 0.43 & 0.5420 \\
Residual $_{\text {Lack offit }}$ & 25.73 & 5 & 5.15 & & \\
Pure error & 18.09 & 3 & 6.03 & & 0.4108 \\
Cor total & 7.65 & 2 & 3.82 & & \\
\hline
\end{tabular}

$* P<0.01$, extremely significant difference. $0.01<P<0.05$, significant difference 
Thus, by using appropriate methods to optimize the fermentation conditions and technology, the product yield can be improved to a certain extent. In recent years, RSM has been widely used in bio-fermentation, food technology optimization and other fields ( $\mathrm{Wu}$ and $\mathrm{Ahn}$, 2018). When compared with the wild-type A. oryzae, engineered $A$. oryzae strains could produce polypeptides from soybean meal fermentation with high efficiency and obvious advantages. The obtained soybean polypeptides products could be further used as substrates or functional additives in food production process and other industries.
Design-expert? Software Factor coding: Actual polypeptide conversion rate

$\mathrm{X} 1=\mathrm{A}:$ Fermentation time $\mathrm{X} 2=\mathrm{B}:$ Fermentation temperature Actual factor $\mathrm{C}:$ inoculation volume $=500$

Design-expert? Software Factor coding: Actual polypeptide conversion rate

$\mathrm{X} 1=\mathrm{A}:$ Fermentation time $\mathrm{X} 2=\mathrm{C}$ : Inoculation volume

Actual factor

B: Fermentation temperature $=32.00$

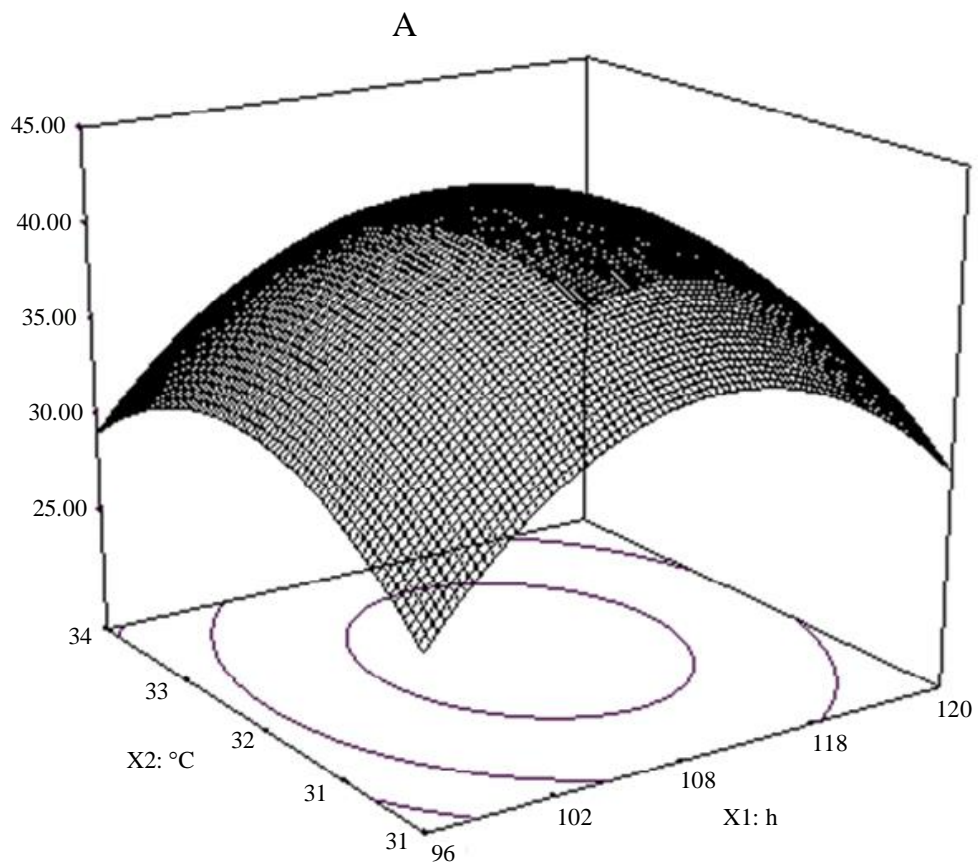

B

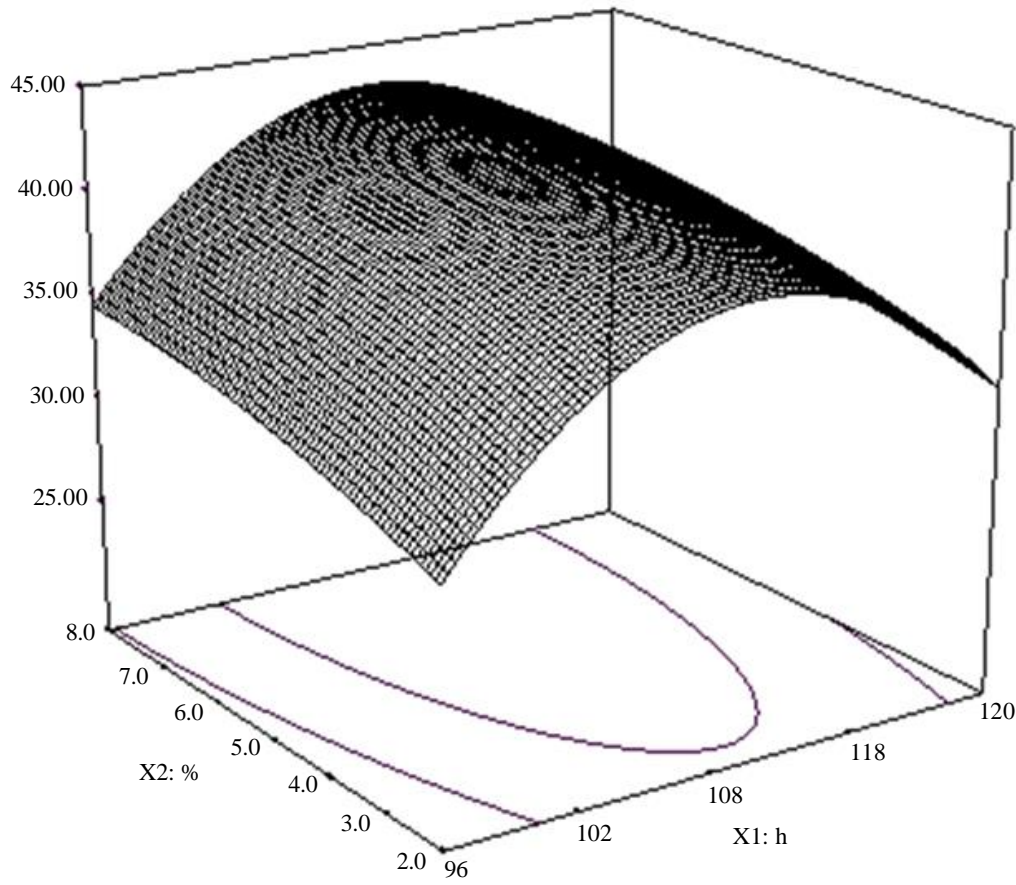


Design-expert? Software

Factor coding: Actual polypeptide conversion rate

$\mathrm{X} 1=\mathrm{B}$ : Fermentation temperature $\mathrm{X} 2=\mathrm{C}$ : Inoculation volume

Actual factor

A: Fermentation time $=108.00$

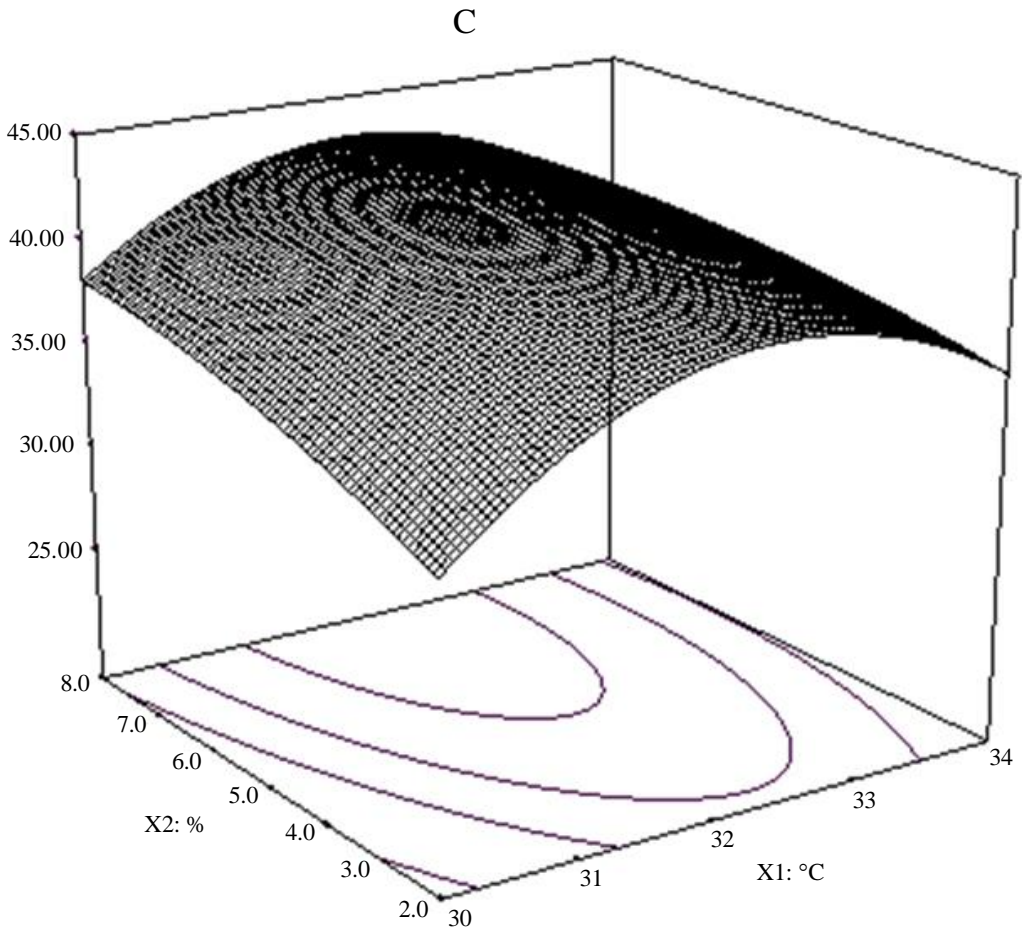

Fig. 9: Response surface of polypeptide conversions representing the interaction between two fermentation variables with the other variable remaining constant. A) Interaction between time and temperature with $4 \%$ inoculum volume; B) Interaction between time and inoculum volume at a temperature of $32 \mathrm{C}$; C) Interaction between temperature and inoculum volume with time of $108 \mathrm{~h}$

\section{Conclusion}

In this study, the fermentation efficiencies of four different novel recombinant engineered A. oryzae strains based on the molecular weight and antioxidant activities of the polypeptides produced had been investigated. The results showed that the proportion of small-molecule peptides produced by engineered $A$. oryzae strains was higher than that produced by wildtype $A$. oryzae. The antioxidant capacity of the engineered strains, especially component I of $A$. oryzae pep, presented varying degrees of improvement. Under optimized fermentation conditions, the polypeptide conversion rate of $A$. oryzae pep reached $40.4 \%$, which was 2.4 times higher than that of the wild-type A. oryzae. These results may help to develop efficient $A$. oryzae strains and effective utilization of soybean meal resources.

\section{Acknowledgment}

This study was funded by the Financial support for Department of Pharmaceutics and Food Science, Tonghua Normal University.

\section{Author's Contributions}

Xiaochun Yu: Participated in the whole experiment process and coordinated the data-analysis and manuscript preparation.

Mingshuang Wang: Participated in part of the experimental design and contributed to the experiment of polypeptides analysis.

Xin Su: Contributed to the optimization of fermentation conditions and coordinated the dataanalysis.

Xuejiao Han: Contributed to the experiment of antioxidant activity.

\section{Conflict of Interest}

The authors have no conflict of interests.

\section{References}

Abe, K., K. Gomi, F. Hasegawa and M. Machida, 2006. Impact of Aspergillus oryzae genomics on industrial production of metabolites. Mycopathologia, 162: 143-153. DOI: 10.1007/s11046-006-0049-2 
Barbesgaard, P., H.P. Heldt-Hansen and B. Diderichsen, 1992. On the safety of Aspergillus oryzae: A review. Applied Microbiol. Biotechnol., 36: 569-572.

DOI: $10.1007 /$ bf00183230

te Biesebeke, R., E. Record and N. van Biezen, 2005. Branching mutants of Aspergillus oryzae with improved amylase and protease production on solidsubstrates. Applied Microbiol. Biotechnol., 69: 44-50. DOI: 10.1007/s00253-005-1968-4

Brown, S.H., L. Bashkirova and R. Berka, 2013. Metabolic engineering of Aspergillus oryzae NRRL 3488 for increased production ofl-malic acid. Applied Microbiol. Biotechnol., 97: 8903-8912. DOI: $10.1007 / \mathrm{s} 00253-013-5132-2$

Chen, L.Y., X.J. Meng, W. Jia, Q.L. Kong and Y.S. Zheng et al., 2004. The study on the antitumor activity and scavenging free radical and immune effect of the water-soluble polysaccharides from A. Persica. L. var. seleropersica. Food Sci., 25: 167-170.

Cotton, F., E. Delobbe and B. Gulbis, 1997. Assessment of a biuret method without concentration step for total protein determination in cerebrospinal fluid. Clin. Biochem., 30: 313-314.

DOI: 10.1016/S0009-9120(97)00038-6

Dai, X.J., M.Q. Liu, H.X. Jin and M.Y. Jing, 2018. Optimisation of solid-state fermentation of Aspergillus niger j1-15 for xylanase production and xylooligosaccharides preparation. Czech J. Food Sci., 29: 557-567. DOI: 10.17221/103/2010-CJFS

Deacon, B.D., 1972. Rapid determination of protein in soybean meals. J. Am. Oil Chem. Soc., 49: 660-661. DOI: $10.1007 / \mathrm{BF} 02609382$

Fang, Y., S. Liu, S. Wang and M. Lv, 2009. Isolation and screening of a novel extracellular organic solvent-stable protease producer. Biochem. Eng. J., 43: 212-215. DOI: 10.1016/j.bej.2008.10.001

Gao, X.M., Y. Li, X.H. Liu, M.H. Huan and J. Ao, 2014. Primary study on production of soybean polypeptide by solid state fermentation. Shandong Agric. Sci., 46: 78-81.

DOI: 10.14083/j.issn.1001-4942.2014.07.003

Gunst, R.F., 2008. Response surface methodology: Process and product optimization using designed experiments. Technometrics, 38: 284-286.

DOI: $10.1080 / 00401706.1996 .10484509$

Han, C.H., J.C. Liu, S.U. Fang and W.C. Hou, 2013. Antioxidant activities of the synthesized thiolcontained peptides derived from computer-aided pepsin hydrolysis of yam tuber storage protein, dioscorin. Food Chem., 138: 923-930.

DOI: 10.1016/j.foodchem.2012.11.101

Hunter, A.J., T.A. Morris, B. Jin, C.P. Saint and J.M. Kelly, 2013. Deletion of creB in Aspergillus oryzae increases secreted hydrolytic enzyme activity. Applied Environ. Microbiol., 79: 5480-5487.

DOI: 10.1128/AEM.01406-13
Ibrahim, H.R., H. Isono and T. Miyata, 2018. Potential antioxidant bioactive peptides from camel milk proteins. Anim. Nutr., 4: 273-280.

DOI: 10.1016/j.aninu.2018.05.004

Lawrence, K.R., C.W. Hastad, R.D. Goodband, M.D. Tokach and M.J. Webster, 2003. Effects of soybean meal particle size on growth performance of nursery pigs. J. Anim. Sci., 81: 2118-2122.

DOI: $10.2527 / 2003.8192118 x$

Li, Y.H., B. Jiang, T. Zhang, W. Mu and J. Liu, 2008. Antioxidant and free radical-scavenging activities of Chickpea Protein Hydrolysate (CPH). Food Chem., 106: 444-450.

DOI: 10.1016/j.foodchem.2007.04.067

Liao, B., J. Jia, X. Li, Y. Zhao and J.K. Li, 2012. Preparation technology of soybean peptides by liquid fermentation. China Brew., 31: 121-124. DOI: 10.3969/j.issn.0254-5071.2012.02.034

Liu, A.J., X.L. Shang, Z.Y. Zhu and J.H. Man, 2009. Analysis of the solid-state fermented soybean meal by monascus. Modern Food Sci. Technol., 25: 149-151. DOI: 10.3969/j.issn.1673-9078.2009.02.009

Liu, L., H. Wang and Q. Liu, 2011. Optimization for solid state fermenting condition of producing soybean peptides from soybean meal powder. Soyb. Sci., 30: 998-1000.

Liu, J., J. Zhou, L. Wang, Z. Ma and G. Zhao et al., 2017. Improving nitrogen source utilization from defatted soybean meal for nisin production by enhancing proteolytic function of Lactococcus lactis F44. Sci. Re., 7: 6189.

DOI: 10.1038/s41598-017-06537-w

Ma, Y.Q., Y. Zhao and Y.G. Shi, 2001. Molecular weight distribution of oligo-peptide in soybean protein hydrolysate. J. Chin. Cereal. Oil. Ass., 16: 15-17.

Mukherjee, R., R. Chakraborty and A. Dutta, 2016. Role of fermentation in improving nutritional quality of soybean meal-a review. Asian-Australas J. Anim. Sci., 29: 1523-1529. DOI: 10.5713/ajas.15.0627

Nath, A., G. Szécsi, B. Csehi, Z. Mednyánszky and G. Kiskó et al., 2017. Production of hypoallergenic antibacterial peptides from defatted soybean meal in membrane bioreactor: A bioprocess engineering study with comprehensive product characterization. Food Technol. Biotechnol., 55: 308-324. DOI: $10.17113 / \mathrm{ftb} .55 .03 .17 .5040$

Olempska-Beer, Z.S., R.I. Merker, M.D. Ditto and M.J. Dinovi, 2006. Food-processing enzymes from recombinant microorganisms-a review. Regul. Toxicol. Pharmacol., 45: 144-158. DOI: $10.1016 /$ j.yrtph.2006.05.001

Ortega, M.A., A.J. Davis, H.R. Boerma and W.A. Parrott, 2016. Suitability of soybean meal from insect-resistant soybeans for broiler chickens. J. Agric. Food Chem., 64: 2209-2213.

DOI: 10.1021/acs.jafc.5b05992 
Ortiz, G.E., D.G. Noseda, M.C.P. Mora, M.N. Recupero and E.O. Albertó, 2016. A comparative study of new Aspergillus strains for proteolytic enzymes production by solid state fermentation. Enzyme Res., 2016: 3016149-3016149. DOI: 10.1155/2016/3016149

Parejo, I., C. Codina, C. Petrakis and P. Kefalas, 2000. Evaluation of scavenging activity assessed by Co(II)/EDTA-induced luminol chemiluminescence and DPPH* $^{*}$ (2,2-diphenyl-1-picrylhydrazyl) free radical assay. J. Pharmacol. Toxicol. Methods, 44: 507-512. DOI: 10.1016/S1056-8719(01)00110-1

Roldan-Carrillo, T., X. Martinez-Garcia, I. Zapata-Penasco, G. Castorena-Cortés and J. Reyes-Avila et al., 2011. Evaluation of the effect of nutrient ratios on biosurfactant production by Serratia marcescens using a Box-Behnken design. Colloids Surf. B Biointerfaces, 86: 384-389. DOI: 10.1016/j.colsurfb.2011.04.026

Rumsey, G.L., A.K. Siwicki, D.P. Anderson and P.R. Bowser, 1994. Effect of soybean protein on serological response, non-specific defense mechanisms, growth and protein utilization in rainbow trout. Vet. Immunol. Immunopathol., 41: 323-339. DOI: 10.1016/0165-2427(94)90105-8

Suetsuna, K., 2000. Antioxidant peptides from the protease digest of prawn (Penaeus japonicus) muscle. Mar. Biotechnol. (NY), 2: 5-10.

DOI: $10.1007 / \mathrm{s} 101269900002$

Wang, Z., Y. Cui, P. Liu, Y. Zhao and L. Wang et al., 2017. Small peptides isolated from enzymatic hydrolyzate of fermented soybean meal promote endotheliumindependent vasorelaxation and ACE inhibition. J. Agric. Food Chem., 65: 10844-10850.

DOI: $10.1021 /$ acs.jafc.7b05026

Wu, W.J. and B.Y. Ahn, 2018. Statistical optimization of medium componentsby response surface methodology toenhance menaquinone-7(vitamin $\mathrm{k} 2$ ) production by Bacillus subtilis. J. Microbiol. Biotechnol. DOI: 10.4014/jmb.1801.01042

Xie, Y., X. Liang, M. Wei, W.H. Zhao and B.S. He et al., 2012. Optimization of glutamine peptide production from soybean meal and analysis of molecular weight distribution of hydrolysates. Int. J. Mol. Sci., 13: 7483-7495. DOI: 10.3390/ijms13067483
Xu, D., L. Pan, H. Zhao, M. Zhao and J. Sun et al., 2011. Breeding and identification of novel koji molds with high activity of acid protease by genome recombination between Aspergillus oryzae and Aspergillus niger. J. Ind. Microbiol. Biotechnol., 38: 1255-1265. DOI: 10.1007/s10295-010-0904-5

$\mathrm{Xu}$, J., Q. Zhao, Y. Qu and F. Ye, 2015. Antioxidant activity and anti-exercise-fatigue effect of highly denatured soybean mealhydrolysate prepared using neutrase. J. Food Sci. Technol., 52: 1982-1992. DOI: $10.1007 / \mathrm{s} 13197-013-1220-7$

Yang, X.J., J.S. Wang, D.H. Lin, Y. Zhou and S. Yang, 2013. Optimization of protein rich in peptides produced by solid state fermentation. Feed Industry, 34: 35-39.

DOI: 10.3969/j.issn.1001-991X.2013.15.009

Yen, G.C. and P.D. Duh, 1993. Antioxidative properties of methanolic extracts from peanut hulls. J. Am. Oil Chen. Soc., 70: 383-386.

DOI: $10.1007 / \mathrm{BF} 02552711$

$\mathrm{Yu}$, M., S. He, M. Tang, Z. Zhang and Y. Zhu et al., 2018. Antioxidant activity and sensory characteristics of Maillard reaction products derived from different peptide fractions of soybean meal hydrolysate. Food Chem., 243: 249-257.

DOI: 10.1016/j.foodchem.2017.09.139

Yu, X.C., S.L. Ma, Y. Xu, C.H. Fu and C.Y. Jiang et al., 2017. Construction and application of a novel genetically engineered Aspergillus oryzae for expressing proteases. Electron. J. Biotechnol., 29: 32-38. DOI: 10.1016/j.ejbt.2017.07.004

Zhao, G., Y. Yao, L. Hou, C. Wang and X. Cao, 2014. Comparison of the genomes and transcriptomes associated with the different protease secretions of Aspergillus oryzae 100-8 and 3.042. Biotechnol. Lett., 36: 2053-2058. DOI: $10.1007 / \mathrm{s} 10529-014-1574-6$

Zheng, L., D. Li, Z.L. Li, L.N. Kang and Y.Y. Jiang et al., 2017. Effects of Bacillus fermentation on the protein microstructure and anti-nutritional factors of soybean meal. Lett. Applied Microbiol., 65: 520-526. DOI: $10.1111 /$ lam.12806 